\title{
Microparasite ecology and health status of common bluestriped snapper Lutjanus kasmira from the Pacific Islands
}

\author{
Thierry M. Work ${ }^{1, *}$, Matthias Vignon ${ }^{2,3}$, Greta S. Aeby ${ }^{4}$ \\ ${ }^{1}$ US Geological Survey, National Wildlife Health Center, Honolulu Field Station, PO Box 50167, Honolulu, Hawaii 96850, USA \\ ${ }^{2}$ Centre de Biologie et d'Ecologie Tropicale et Méditerranéenne, UMR 5244 CNRS-EPHE-UPVD, avenue Paul Alduy, \\ 66860 Perpignan Cedex, France \\ ${ }^{3}$ Centre de Recherches Insulaires et Observatoire de l'Environnement (CRIOBE), USR 3278 CNRS-EPHE, BP 1013 Papetoia \\ Moorea, French Polynesia \\ ${ }^{4}$ Hawaii Institute of Marine Biology, PO Box 1346, Kaneohe, Hawaii 96744, USA
}

\begin{abstract}
Common bluestriped snappers Lutjanus kasmira were intentionally introduced into Hawaii from the South Pacific in the 1950s and have become well established throughout the archipelago. We examined health, prevalence and infection intensity of 2 microparasites, coccidia and epitheliocystis-like organisms (ELO), in L. kasmira from their introduced and native range including the islands where translocated fish originated (Tahiti and Marquesas Islands, French Polynesia) and from several other islands (American Samoa, Fiji and New Caledonia). In addition, we did a longitudinal survey of these parasites in the introduced range. Coccidia and ELO were widely distributed and were found on all islands except for New Caledonia. Health indices, as measured by overall organ lesions, body condition and parasite intensity, indicated that fish from Samoa were the least healthy, and fish from Midway (Hawaiian Archipelago) were the healthiest. Microparasite diversity was highest on Midway and Hawaii and lowest on New Caledonia. Infection of coccidia followed an asymptotic size-prevalence curve, whereas that of ELO peaked at larger size classes $(27.8 \mathrm{~cm})$. Prevalence and aggregation of both parasites in the host varied dynamically over 8 yr, with prevalence and aggregation of coccidia being consistently higher and lower, respectively, than ELO. We hypothesize that these parasites are enzootic to the Hawaiian Islands and were not introduced with fish from Tahiti or the Marquesas Islands. Host response and aggregation parameters suggest that coccidia exert a negative effect on their host and probably have an indirect life cycle, whereas ELO appears less pathogenic and has a direct life cycle.
\end{abstract}

KEY WORDS: Common bluestriped snapper ' Lutjanus kasmira ' Coccidia • Pathology · Epitheliocystis-like organism • Prevalence · Pacific Islands

Resale or republication not permitted without written consent of the publisher

\section{INTRODUCTION}

The common bluestriped snapper Lutjanus kasmira (Forsskål, 1775) (Lutjanidae) is a reef fish found throughout the Indo-Pacific (Randall 2005). Because of the lack of highly commercially valuable fish species such as groupers and snappers (Oda \& Parrish 1981, Randall 1987), this fish was intentionally introduced off the island of Oahu, Hawaii, from the Marquesas Islands and Tahiti in the 1950s to enhance local coastal fisheries. Since its introduction to Oahu, L. kasmira has become extremely abundant and has successfully spread throughout the entire Hawaiian Archipelago, from Midway in the northwest to the island of Hawaii in the southeast (Friedlander et al. 2002). Since its introduction, this snapper has become the focus of considerable attention in the scientific and fishing community because of its possible deleterious effects on local marine communities. However, evidence is scant for dietary overlap or competition between L. kasmira and 
native fish, nor have they been incriminated in consumption of native fish (Oda \& Parrish 1981). In contrast, L. kasmira are often found schooling with native goatfish, and asymmetrical competition occurs with one species, Mulloidychthies vanicolensis, the latter being displaced higher into the water column, possibly making the native goatfish more susceptible to predation (Schumacher \& Parrish 2005).

In general, animals that colonize remote islands are thought to have a low probability of introducing parasites from their native range, in part because only the fittest animals are thought capable of long-distance migrations (Torchin et al. 2003). The case of the Lutjanus kasmira in Hawaii is different in that this species was deliberately and repetitively introduced in large numbers (Randall 1987), thus presumably enhancing the likelihood of parasite introductions into Hawaii (Randall 1987). Several reports exist on investigation of potentially invasive nematodes in L. kasmira from Hawaii (Rigby \& Font 1997, Font \& Rigby 2000), and a recent comprehensive study of overall macroparasite fauna of $L$. kasmira from South Pacific islands suggests that most of the macroparasites found in L. kasmira from Hawaii were introduced (Vignon et al. 2009).

In contrast, relatively less information exists on microparasites in L. kasmira (and tropical wild marine fish in general) in part because these are more difficult to detect. One report documented a high prevalence of merozoites of a coccidian parasite and a relatively lower prevalence of infections of epitheliocystis-like organisms (ELO) in L. kasmira from Oahu where the fish were initially introduced (Work et al. 2003). However, the role of $L$. kasmira in introducing potential microparasites into Hawaiian marine ecosystems is unclear, and it is unknown how widespread these microparasites are in fish populations within the Hawaiian Archipelago or the Pacific. In addition, we do not have data on the potential effects of these parasites on the host.

Unless parasites can be documented to cause significant mortality (epizootics), determining whether or not they have an adverse impact on hosts based on cross-sectional age-prevalence surveys can be difficult because their effects can be subtle (McCallum \& Dobson 1995). Controlled experimental studies exposing hosts to parasites are ideal to document effects, but for marine ecosystems the life cycles of many parasites are unknown, precluding their use. However, clues to effects of parasites on hosts can be gained from cross-sectional surveys. For example, decreasing prevalence of parasites with age can be caused by parasite-induced host mortality or successful host immune response and clearance of parasites (Wilson et al. 2001). Sorting this out in absence of knowledge on immune status of the host can be difficult, and for most helminth surveys, for example, host response to the parasite is often not examined, although exceptions to this exist (Rigby \& Dufour 1996). In contrast, histologic examination of tissues for microparasites usually includes documentation of host response and pathologies that may not be evident from routine gross examination of tissues.

The objectives of the present study were to document: (1) the geographic extent of microparasites in Lutjanus kasmira from both the native range, where the fish originated (Tahiti and the Marquesas Islands in French Polynesia), and the introduced range (Hawaiian Archipelago); (2) the general health status of L. kasmira in these islands; (3) the spatio-temporal epidemiological variability in L. kasmira within the introduced range; and (4) the potential effects of microparasites on the health of L. kasmira in their introduced range.

\section{MATERIALS AND METHODS}

Fish from Oahu and Maui were collected by hook and line or by pole spear at depths ranging from 15 to $80 \mathrm{~m}$. For the temporal study, an equal number of fish were caught at the same 5 locations off Oahu each year between 2001 and 2008 as part of a long-term water quality study carried out by the City and County of Honolulu. We measured whole weight $(0.1 \mathrm{~g})$ and total and fork length $(0.1 \mathrm{~cm})$. Body condition index (whole weight/total length ${ }^{3}$ ) was calculated as described by Le Cren (1951) because it is a good indicator of the general well-being of a fish (Bolger \& Connolly 1989). All fish underwent a systematic external and internal examination, and representative tissues including gill, skin, muscle, brain, liver, spleen, cranial and caudal kidney and swim bladder were preserved in $10 \%$ neutral buffered formalin, embedded in paraffin, sectioned at $5 \mu \mathrm{m}$ and stained with hematoxylin and eosin. Parasites were identified as belonging to one of the following groups: (1) coccidia, (2) ELO, (3) helminths, (4) myxosporea or (5) microsporea.

Microscopic lesions for each organ were assigned a score according to a scheme simplified from Bernet et al. (1999). Briefly, lesions were characterized as atrophy, inflammation or necrosis and assigned a score of 1, 2 or 3, respectively. These scores were a modification of Bernet et al. (1999), whereby the magnitude of the score reflected the reversibility of damage (e.g. atrophy is a reversible process, necrosis is not). Lesions were further assigned a subjective severity score: mild (1), moderate (2) or severe (3). Lesion type multiplied by lesion severity was summed for each organ to arrive at a lesion score for that organ. An average lesion score was then computed for each fish by dividing the sum total lesion score for all organs by the number of organs examined. 
To ensure a sufficient sample size for meaningful statistics, we evaluated the effects of parasites on fish only for those parasites that infected $\geq 20 \%$ of 700 fish examined in the study ( $\geq 140$ fish). To assess parasite intensity, number of clusters of coccidia per spleen section or numbers of ELO per caudal kidney section were quantified. To evaluate host response to coccidia, a subset of fish from Oahu was randomly selected for enumeration of coccidia by digital photography (Schwindt et al. 2006). Briefly, slides of 1 to 2 longitudinal histological sections of entire spleens were scanned, and the total area of the spleen section and fraction of the section occupied by parasites or melanized macrophage centers (MMCs) were calculated using SigmanScan (Systat Software); host response to coccidia consisted of envelopment by MMCs. Because host response to ELO was more or less binary, it was classified as mild (no response or, rarely, mild lymphoid infiltrates) or chronic (presence of cartilaginous capsule around ELO) (Work et al. 2003).

Simple linear regression was used to evaluate the relationship between intensity of coccidia infection and numbers of MMC and between numbers of aggregates of aplicomplexa and the percent of organ occupied by parasites. Mean numbers of ELO for fish manifesting mild or chronic responses were compared using a Student's $t$-test (Daniel 1987). A chi-square test was used to evaluate organ tropism of ELO or coccidia and its potential effect on host survival (Lester 1984). To assess overall health of fish, sampling areas (Hawaii, Maui, Oahu, French Frigate Shoals, Midway, Tahiti, Marquesas, Fiji, Samoa and New Caledonia) were ranked 1 to 10 as to mean body condition (high to low), mean parasite intensity for coccidia and ELO (low to high) and mean lesion score (low to high). A mean overall score was then calculated for each area and served as the health index, with a high score indicating an unhealthy fish population. A similar process was used to assess health of fish between years on Oahu for 2001-2008 (ranked 1 to 9). Multiple linear regression was used to assess annual prevalence of ELO and coccidia versus health index between 2001 and 2008. Simpon's diversity index (1-D) was used to assess microparasite diversity across islands (Simpson 1949). Body condition indices for fish in introduced (Hawaiian Archipelago) versus native (all other islands) ranges were compared using $t$-tests. Alpha for all comparisons was set at 0.05 .

Parasites in animals typically adopt a distribution that is most closely approximated by the negative binomial, where the majority of animals are uninfected and a few animals have heavy infections (Shaw \& Dobson 1995). Two measures of the degree of aggregation of parasite distribution include the variance to mean ratio (Anderson \& Gordon 1982) and maximum likeli- hood estimates of $k$ (Bliss \& Fisher 1953); the former increases and the latter decreases with increasing parasite aggregation within the host. Measures of aggregation have been used to explain patterns in parasite-host ecology such as the shape of size-prevalence curves and potential effects of parasites on host fitness (Anderson \& Gordon 1982). Maximum likelihood estimates of $k$ (Bliss \& Fisher 1953) were analyzed using $\mathrm{R}$ (Ihaka \& Gentleman 1996), and variance to mean ratios were analyzed by size class for sample sizes $\geq 30$ individuals (Pacala \& Dobson 1988). Maximum likelihood $k$ and variance to mean ratios were also calculated across years for fish from Oahu and compared to parasite intensity and prevalence. Estimate ages (yr) of Lutjanus kasmira were calculated based on total length, based on a Von Bertalanffy growth model (MoralesNin \& Ralston 1990).

\section{RESULTS}

We sampled a total of 700 fish from Hawaii $(n=27)$, Maui $(\mathrm{n}=45)$, Oahu ( $\mathrm{n}=500)$, French Frigate Shoals $(\mathrm{n}=20)$, Midway $(\mathrm{n}=19)$, Marquesas $(\mathrm{n}=20)$, Tahiti $(\mathrm{n}=30)$, American Samoa $(\mathrm{n}=20)$, Fiji $(\mathrm{n}=11)$ and New Caledonia $(n=8)$. Overall, by histology, coccidia were the most common parasites (55\%), followed by ELO $(22 \%)$, helminths $(10 \%)$, microsporidia $(2 \%)$ and myxosporea $(1 \%)$. ELO and coccidia were found in both spleen and caudal kidney. ELO was significantly more likely to be located in the caudal kidney, whereas coccidia were significantly more likely to be located in the spleen $\left(\chi^{2}=362\right.$, p $\left.<0.001\right)$, with coccidia more likely to infect both organs. For coccidia, the probability of both kidney and spleen independently being infected (0.09) was greater than both being concurrently infected (0.04). In contrast, for ELO, the probability of both organs independently being infected (0.006) was less than the probability of both being concurrently infected (0.05). Across islands, dual infection with coccidia and ELO was seen in Samoa $(20 \%)$, Oahu (18\%), Maui (11\%) and Marquesas (5\%). Helminths infected the widest variety of organs with liver $(23 \%)$, gill $(22 \%)$, skeletal muscle $(14 \%)$ and heart $(12 \%)$ comprising the majority, and spleen, caudal kidney, brain, pancreas and gonads each comprising $<10 \%$. Microsporidia infected mainly liver (92\%) followed by skeletal muscle (8\%). Myxosporea were mainly found in the spleen $(57 \%)$ followed by liver $(28 \%)$ and cranial kidney $(15 \%)$.

In the Hawaiian Archipelago, prevalence of coccidia was similar on Oahu, Maui and French Frigate Shoals, but decreased on Hawaii and Midway. In contrast, prevalence of ELO on Oahu was highest but dropped progressively in adjacent islands to the 
southeast and northwest. Prevalence of coccidia consistently exceeded that of ELO for all islands (Fig. 1A). According to the health score, fish from Samoa were the least healthy, whereas fish from Midway were the healthiest. Diversity of microparasites was highest on Midway and lowest in New Caledonia, and there was no significant relationship between parasite diversity and health index (Fig. 1B). Body condition index (mean $\pm \mathrm{SD}$ ) of fish from the introduced range in the Hawaiian Archipelago $(0.0154 \pm 0.00122)$ was significantly greater $(t=-3.512, \mathrm{p}<0.001)$ than that of fish from the native range $(0.0148 \pm 0.0018)$.

On Oahu, fish acquired ELO and coccidia at about 19 to $20 \mathrm{~cm}$ (i.e. about 1 to $2 \mathrm{yr}$ old) and prevalence of both microparasites increased intermittently as fish grew
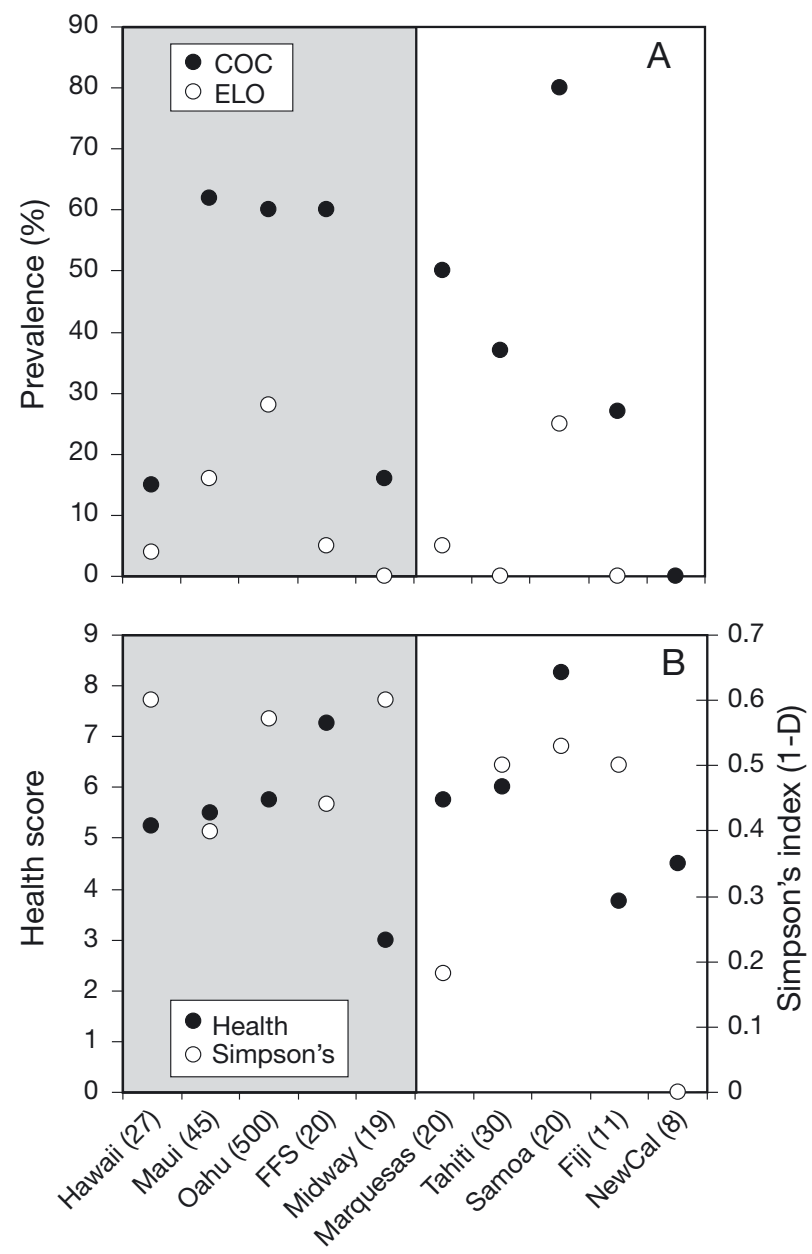

Fig. 1. Lutjanus kasmira. (A) Prevalence of coccidia (COC) and epitheliocystis-like organisms (ELO) in L. kasmira and (B) health score (high is poor health) and Simpson's diversity index (1-D, 0 low diversity) along an east to west longitudinal gradient on 10 Pacific islands partitioned by introduced (shaded) and native (non-shaded) ranges. FFS: French Frigate Shoals; NewCal: New Caledonia. Number in parentheses indicates sample size for each island. Fish were introduced to Hawaii from Tahiti and the Marquesas Islands
(Fig. 2A), reaching $100 \%$ in larger individuals $(>30 \mathrm{~cm})$ for coccidia but $0 \%$ in those size classes for ELO. Variance to mean ratios for coccidia increased with age but remained steady, and increased only for larger size classes (>26.7 cm) for ELO (Fig. 2B). Maximum likelihood $k$ increased (decreased parasite aggregation) with size for both ELO and coccidia, but dropped in larger age classes (>26.7 cm) for ELO (Fig. 2C).

On Oahu, annual prevalence of coccidia ranged from 48 to $80 \%$, whereas that of ELO ranged from 12 to $48 \%$. Annual prevalence of both microparasites ran-
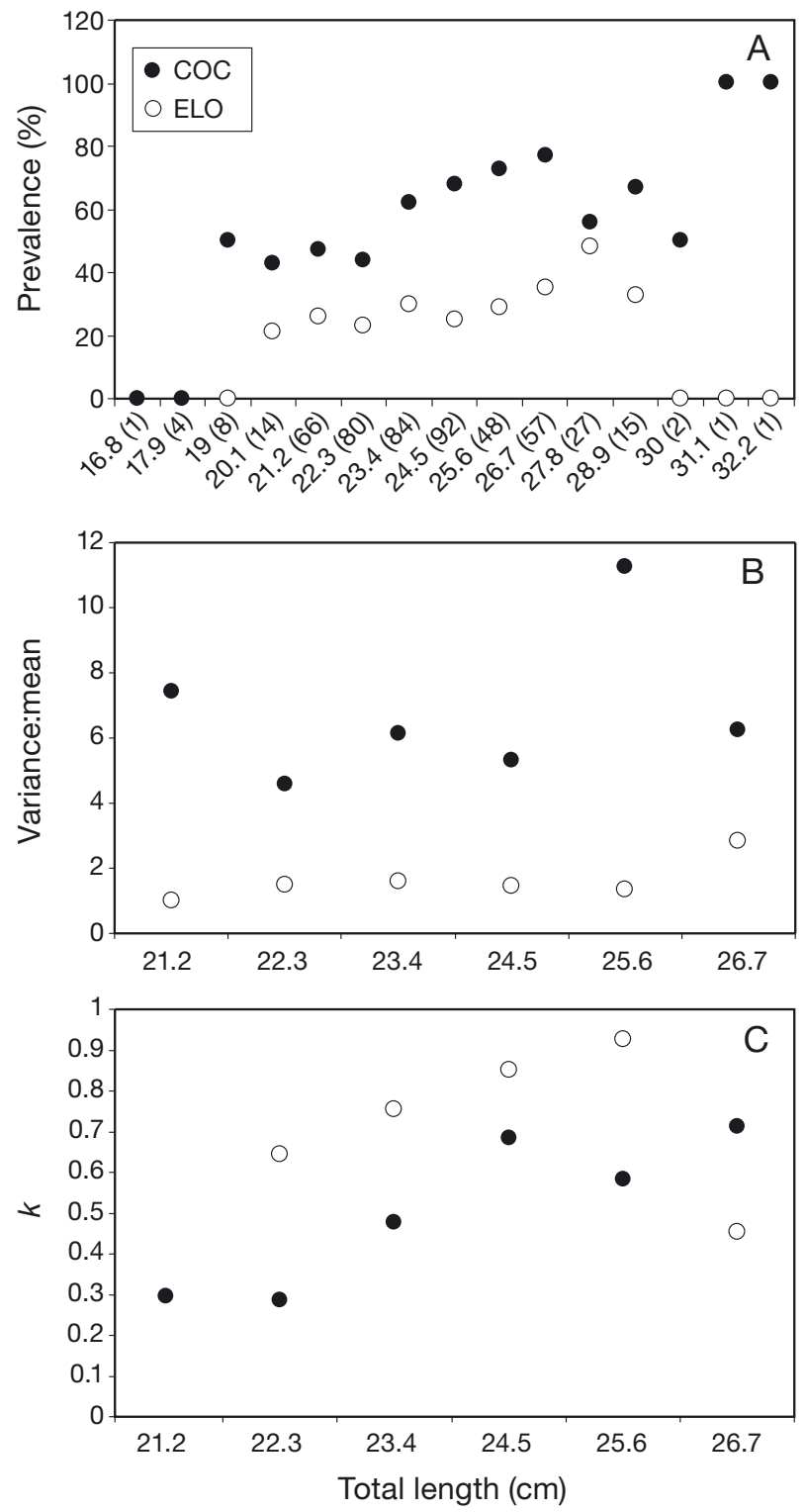

Fig. 2. Lutjanus kasmira. Fish caught off Oahu 2001-2008 (A) Size-prevalence curves for coccidia (COC) and epitheliocystis-like organisms (ELO). Number in parentheses is sample size. (B) Variance to mean ratios for size classes of fish with $n \geq 30$. (C) Maximum likelihood $k$ for size classes of fish with $\mathrm{n} \geq 30$ 
domly fluctuated (Fig. 3A). There was no significant relationship between prevalence of coccidia and ELO across years. As measured by variance to mean ratio, peaks in aggregation were seen for coccidia in 2001, 2003 and 2007 and for ELO in 2002 (Fig. 3B). As measured by maximum likelihood $k_{\text {, }}$ aggregation was highest in 2001, 2006 and 2008 for coccidia and in 2001, 2004 and 2008 for ELO (Fig. 3C). On Oahu, the health index increased significantly with prevalence of ELO and coccidia ( $F=17.635, \mathrm{p}=0.005)$ (Fig. 3D).

Prevalence and intensity of infection were significantly related by linear regression for both coccidia $\left(\mathrm{R}^{2}=0.64, F=12.3, \mathrm{p}=0.01\right)$ and $\operatorname{ELO}\left(\mathrm{R}^{2}=0.9, F=\right.$ $66.9, \mathrm{p}<0.001$; Fig. $4 \mathrm{~A})$. For coccidia $\left(\mathrm{R}^{2}=0.95, F=\right.$ $114.4, \mathrm{p}<0.001)$, aggregation as measured by maximum likelihood $k$ decreased significantly with increasing prevalence $\left(\mathrm{R}^{2}=0.95, F=114.4, \mathrm{p}<0.001\right)$, but the relationship was not significant with ELO. Aggregation decreased significantly more rapidly with increasing prevalence in coccidia compared to ELO $(t=38622$, $\mathrm{p}<0.001$; Fig. 4B). There was no significant relationship between variance to mean ratio and prevalence for either parasite (data not shown). The relationship between log variance to log mean parasite intensity for coccidia $(F=6.760, \mathrm{p}=0.041)$ and ELO $(F=8.948, \mathrm{p}=$ 0.024 ) were significantly related; however, their slopes were $<1$ and did not differ significantly.
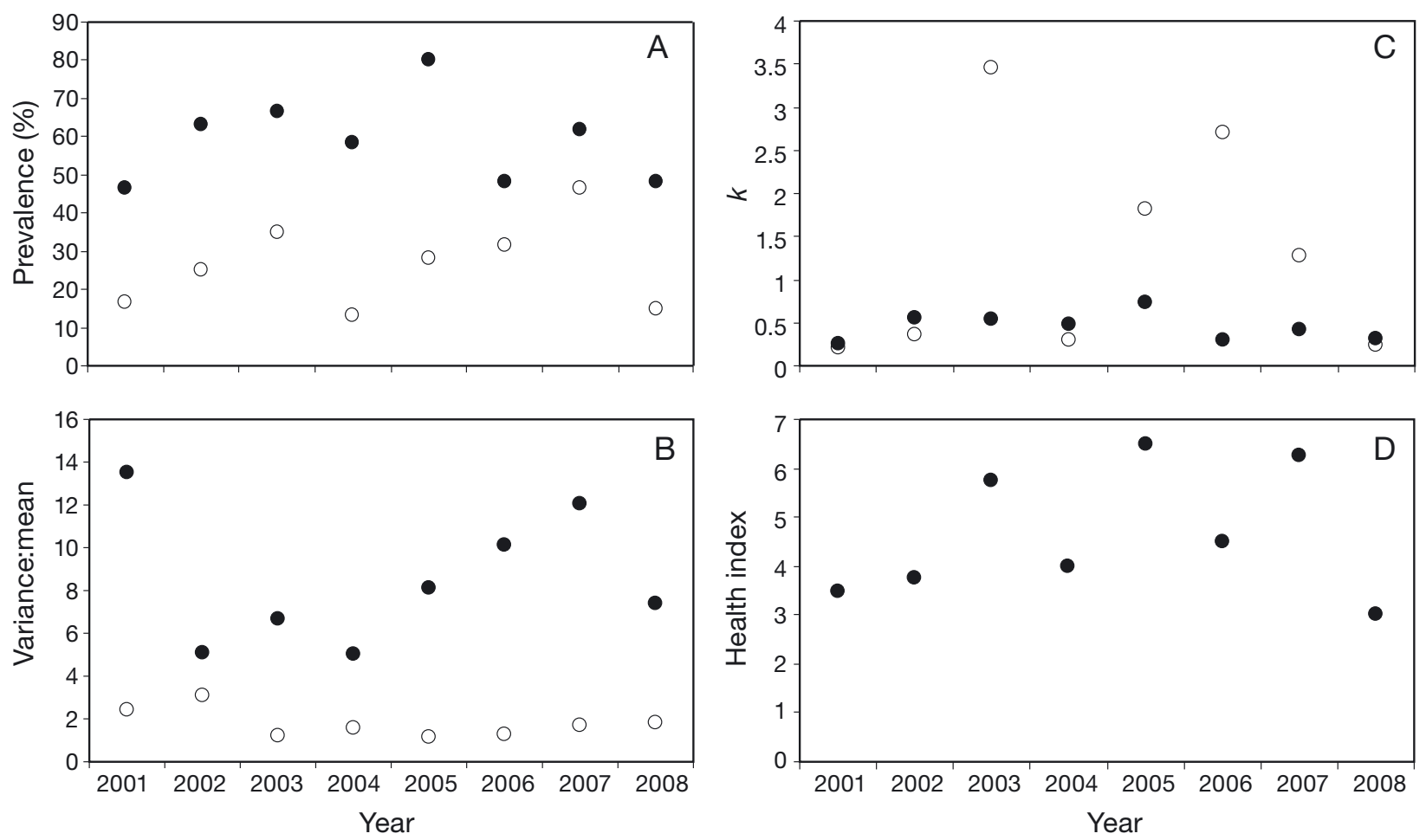

\section{DISCUSSION}

Overall, coccidia and ELO were the most abundant and widely distributed microparasites seen in L. kasmira in the tropical Pacific, and consistently higher prevalence of coccidia indicates that this organism more efficiently parasitizes L. kasmira than ELO. This is supported by size-prevalence curves, where ELO are detected later in life than coccidia. Prevalence of coccidia and ELO was highest in Samoa and around the islands where snappers were introduced (i.e. Oahu) than in the range from where they originated (i.e. Tahiti and Marquesas Islands). In the Hawaiian Archipelago, prevalence of both microparasites progressively decreased southeast and northwest from the release island (Oahu). Given the relatively small sample size in New Caledonia and Fiji, the maximum $95 \%$ likely prevalence of coccidia and ELO would have been 23 and $31 \%$, respectively (Post \& Millest 1991). The lowest detected prevalences for coccidia and ELO were 16 and $4 \%$, so, in theory, our sample size should have been sufficient to detect these organisms in these islands, suggesting that these parasites are rare to absent in those particular ecosystems.

The patterns of decreasing prevalence of parasites with distance from Oahu in the Hawaiian Archipelago can be explained in 2 ways. Either these micropara-

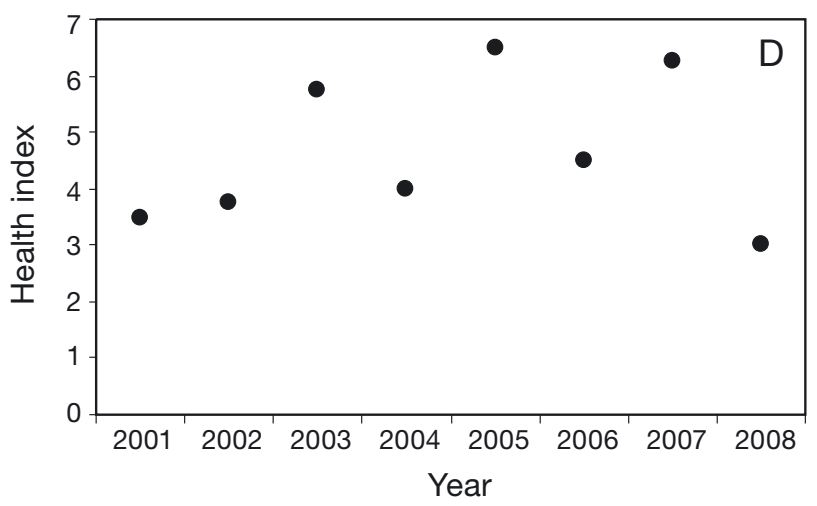

Fig. 3. Lutjanus kasmira. Fish caught off Oahu 2001-2008 (A) Prevalence of coccidia and epitheliocystis-like organisms (ELO) by year $(\mathrm{n}=60)$. (B) Variance to mean ratio by year for coccidia and ELO. (C) Maximum likelihood $k$ by year for coccidia and ELO.

(D) Health index by year (high is poor health). For (A-C), solid circles are coccidia and open circles are ELO 

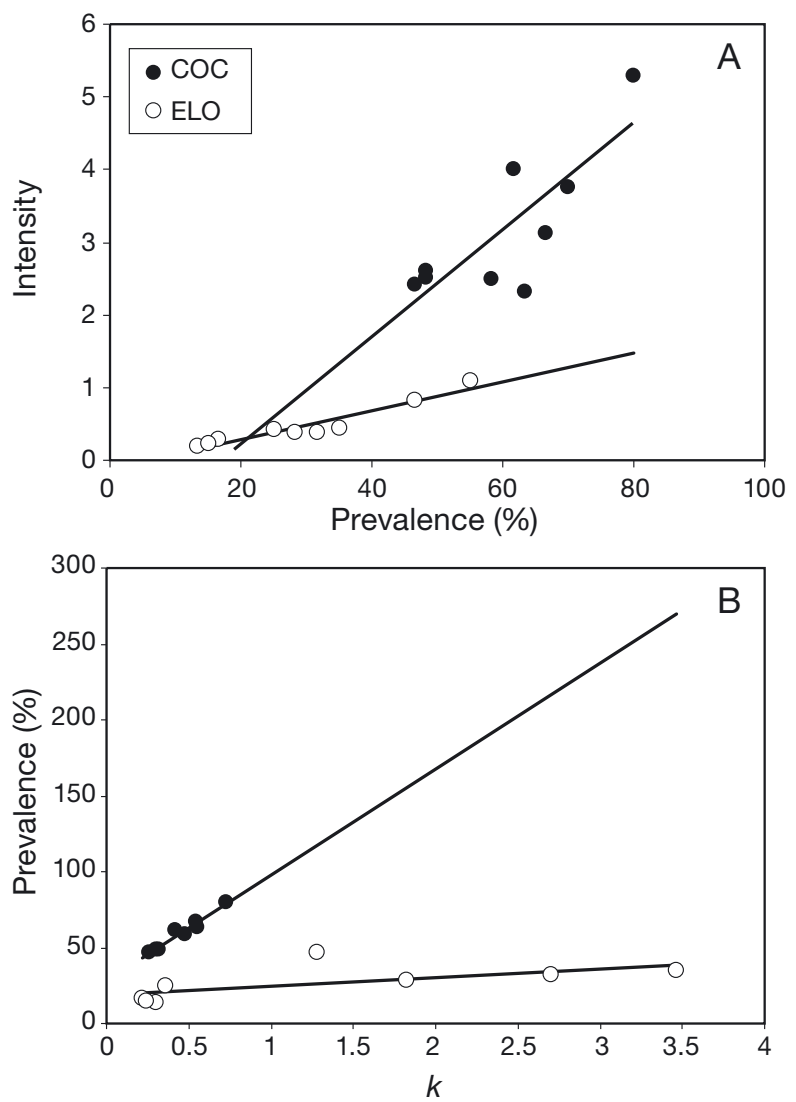

Fig. 4. Lutjanus kasmira. Fish caught off Oahu (A) Prevalence versus intensity of infection for coccidia (COC) and epitheliocystis-like organisms (ELO). Regression values for coccidia $\left(\mathrm{R}^{2}=0.64, F=12.3, \mathrm{p}=0.01\right)$ and ELO $\left(\mathrm{R}^{2}=0.9, F=66.9, \mathrm{p}<\right.$ 0.001 ) were both significant. (B) Maximum likelihood $k$ versus prevalence for coccidia $\left(\mathrm{R}^{2}=0.95, F=114.4, \mathrm{p}<0.001\right)$ and ELO $\left(R^{2}=0.40, F=3.982, p=0.093\right)$

sites are enzootic to the Hawaiian Archipelago, and newly introduced Lutjanus kasmira acquired them progressively from native fauna, or these microparasites were introduced into Oahu from Tahiti and the Marquesas Islands and spread to adjoining islands. There is little evidence that larval fish play a significant role in the geographic spread of parasites, at least for helminths (Rigby \& Dufour 1996, Cribb et al. 2000) and introduction of these parasites into Hawaii from Tahiti and the Marquesas Islands would argue against the parasite release hypothesis stipulating that fish leave their enzootic parasites behind when colonizing new regions (Torchin et al. 2003). However, these fish did not arrive at Hawaii naturally, so we are unsure whether these two concepts would apply in this instance. One other ancillary line of evidence suggests that these parasites were acquired by fish in Hawaii: fish in the Hawaiian Archipelago were in better body condition than those in the native range. A similar phenomenon was seen in introduced green crabs and was explained, in part, by reduced parasite loads in intro- duced versus native crabs in the same ecosystem (Torchin et al. 2001), thus supporting the parasite release hypothesis. Confirming this, however, would require us to examine parasite loads of snappers versus native fish in Hawaii. We cannot explain why diversity of parasites was higher on Midway and Hawaii. The colonization time hypothesis suggests that parasite diversity increases with residence time in introduced fish (Guegan \& Kennedy 1993), so presumably for the Hawaiian Archipelago parasite diversity should have been highest on Oahu.

Lesion scoring has been used successfully to objectively assess geographic variation in fish health (Bernet et al. 1999). Based on a combination of body condition, intensity of coccidia and ELO and lesion scores, Lutjanus kasmira from American Samoa were the least healthy and those from Midway (Hawaii) the healthiest. The overall health status of $L$. kasmira throughout the Hawaiian Archipelago was similar to the natural range. There was no relationship between diversity of parasites and health status of fish. Evidently, health status and parasite diversity operate differently at different scales; whereas no relationship existed here between host health and parasite diversity, on an ecosystem level, others have found that healthier ecosystems had a higher diversity of parasites (Hudson et al. 2006). On the other hand, health status of fish on Oahu decreased significantly with increasing prevalence of both ELO and coccidia, suggesting that combined parasite burdens have a negative cost to the host.

The size-prevalence curve for coccidia was compatible with a Type 2 curve, where prevalence increases to asymptotic levels, whereas the curve for ELO with a peak in middle age classes and a decrease in larger age classes was compatible with a Type 3 curve (Wilson et al. 2001). Type 2 curves are characteristics of a host-parasite system where rate of acquisition of parasites through time is constant, as is parasite-induced mortality. Type 3 curves can be explained by parasiteinduced mortality, acquired immunity or age-related changes in infection or exposure or probability of detecting infection (Wilson et al. 2001). Given that the same techniques to detect parasites were used for all age classes, age-related changes in probability of detection probably does not explain these findings. Low sample sizes for larger age classes could explain the lack of ELO in larger size classes; however, an earlier study with a smaller sample size showed similar size-prevalence curves for both organisms in snappers (Work et al. 2003), suggesting that loss of ELO in older age classes is a real phenomenon.

The evidence for effects of ELO and coccidia on hosts using measures of aggregation in the present study is mixed. For both parasites, the slope of log variance to log mean parasite intensity was $<1$, suggesting para- 
site-induced mortality (Anderson \& Gordon 1982). On the other hand, aggregation as measured by variance to mean ratios and maximum likelihood $k$ decreased with age for coccidia and ELO, but increased at high age classes for ELO, suggesting parasite-induced host mortality for ELO but not coccidia. Anderson \& Gordon (1982) stated that increased variance to mean ratios with age was suggestive of parasite-induced host mortality, but cautioned that this metric was heavily influenced by sample size. Pacala \& Dobson (1988) and Shaw \& Dobson (1995) argued that, given sufficient sample sizes $(\mathrm{n} \geq 30)$, a decrease in aggregation of parasites as measured by maximum likelihood $k$ with age was indicative of parasite-induced host mortality, density-dependent parasite mortality or parasite-induced changes in host susceptibility. Variance to mean ratios and maximum likelihood $k$ are measures of 2 different aspects of aggregation. Scott (1987) argued that variance to mean ratio is more indicative of the length of the tail of the distribution and is a more appropriate measure of aggregation when means differ between samples, whereas maximum likelihood $k$ is more reflective of the left shift of the distribution.

Immunological response of the fish host to these agents and location in organs may provide additional clues as to effects of these parasites on the host. Lutjanus kasmira responded to coccidia infection in the spleen with MMCs that increased significantly with parasite numbers. However, MMC and parasite numbers increased with age, and this has been seen in other fish species such as perch (Brown \& George 1985). Increased immune response to increased parasites has to exact some energetic costs to the host. The significantly higher rate of decrease in aggregation with prevalence for coccidia versus ELO also is suggestive of parasite aggressiveness in colonizing the host; the higher the prevalence, the more heavily infected the hosts. The fact that both parasites colonized 2 organs can be used to discern potential effects on the host. For coccidia, the product of the independent probability of coccidia infection in kidney or spleen was greater than the probability of dual infection, suggesting that they have detrimental effects (Lester 1984), whereas this was not the case for ELO. In contrast to coccidia, L. kasmira respond to ELO by formation of a cartilaginous capsule that effectively walls off the parasite and appears to limit spread of infection within the affected organ. Thus ELO is more characteristic of a chronic disease, whereas coccidia infection is acute with a more rapid onset, a fact substantiated by the earlier acquisition of this parasite in the fish's life. Based on host response, host immunity and parasite clearance rather than parasite-induced mortality would explain the Type 3 size-prevalence curve for ELO.
Prevalence and aggregation of both parasites in Lutjanus kasmira on Oahu as measured by variance to mean ratio and maximum likelihood $k$ were temporally dynamic. The consistently lower prevalence of ELO over time indicates that this organism consistently underperforms against coccidia in parasitizing Lutjanus kasmira. Annual peaks in aggregation (many hosts with few parasites) would be suggestive of pulses of many uninfected hosts entering the population that year. In controlled experiments, Scott (1987) noted that as a parasite spread through a population, aggregation increased and then decreased precipitously with population crashes. The life cycles of the coccidia and ELO infecting L. kasmira are unknown; however, aggregation may also provide clues to life history of these parasites. Parasites with low maximum likelihood $k$ typically have indirect life cycles (Shaw \& Dobson 1995), suggesting that coccidia with their low maximum likelihood $k$ would have a similar life cycle. The relationship of prevalence to parasite intensity for coccidia would seem to confirm this, in that only $64 \%$ of the variation in parasite intensity was explained by prevalence. This suggests a more complex system, and many coccidia do indeed have complex life cycles involving invertebrate intermediate hosts (Overstreet et al. 1984). In contrast, prevalence of ELO (a parasite with high maximum likelihood $k$ and low aggregation) was $90 \%$ explained by parasite intensity, suggesting a simpler system of direct host-to-host transmission. Empirical transmission studies would be needed to confirm this; however, epitheliocystis is thought to be transmitted by direct contact (Hoffman et al. 1969).

We conclude that coccidia and ELO are distributed throughout most of the Pacific islands. We suspect that these organisms naturally occur in the Hawaiian Archipelago, and that they were most likely acquired by Lutjanus kasmira after translocation. Future studies to confirm this might entail molecular analyses of these parasites along a geographic gradient to assess relatedness. Coccidia in L. kasmira probably have an indirect life cycle and exert a negative effect on their host based on organ tropism, organ burden, host response and degree of aggregation. In contrast, ELO appear to be more benign and most likely have a direct life cycle, at least for the size classes of animals examined in the present study. Parasites are suspected to affect the outcome of invasions in marine systems in that detrimental effects of parasites are strongly minimized by costly defenses, and release from parasites allows reallocation of energetic resources to other functions which might give a competitive advantage of introduced over endemic species (Torchin et al. 2002). In the present study, L. kasmira have better body condition in their introduced range but still remain parasitized by 2 microparasites, so other factors such as decreased pre- 
dation may have largely contributed to the successful introduction and rapid spread of this snapper throughout the Hawaiian Archipelago.

Acknowledgements. P. Sasal, R. Cole, W. Font and anonymous reviewers kindly provided constructive comments. Mention of products does not imply endorsement by the US Government.

\section{LITERATURE CITED}

Anderson RM, Gordon DM (1982) Processes influencing the distribution of parasite numbers within host populations with special emphasis on parasite-induced host mortalities. Parasitology 85:373-398

Bernet D, Schmidt H, Meier W, Burkhardt-Holm P, Wahli T (1999) Histopathology in fish: proposal for a protocol to assess aquatic pollution. J Fish Dis 22:25-34

Bliss CI, Fisher RA (1953) Fitting the negative binomial distribution to biological data. Biometrics 9:176-200

Bolger T, Connolly PL (1989) The selection of suitable indices for the measurement and analysis of fish condition. J Fish Biol 34:171-182

Brown CL, George CJ (1985) Age-dependent accumulation of macrophage aggregates in the yellow perch, Perca flavescens (Mitchill). J Fish Dis 8:135-138

Cribb TH, Pichelin S, Dufour V, Bray RA and others (2000) Parasites of recruiting coral reef fish larvae in New Caledonia. Int J Parasitol 30:1445-1451

Daniel WW (1987) Biostatistics: a foundation for analysis in the health sciences. John Wiley \& Sons, New York

Font WF, Rigby MC (2000) Implications of a new Hawaiian host record from blue-lined snappers Lutjanus kasmira: Is the nematode Spirocamallanus istiblenni native or introduced? Bishop Mus Occas Pap 64:53-56

Friedlander A, Parrish JD, DeFelice RC (2002) Ecology of the introduced snapper Lutjanus kasmira (Forsskal) in the reef fish assemblage of a Hawaiian bay. J Fish Biol 60:28-48

> Guegan JF, Kennedy CR (1993) Maximum local helminth parasite community richness in British freshwater fish: a test of the colonization time hypothesis. Parasitology 106:91-100

Hoffman GL, Dunbar CE, Wolf K, Zwillenberg LO (1969) Epitheliocystis, a new infectious disease of the bluegill (Lepomis macrochirus). Antonie Leeuwenhoek 35:146-158

Hudson PJ, Dobson AP, Lafferty KD (2006) Is a healthy ecosystem one that is rich in parasites? Trends Ecol Evol 21: 381-385

Ihaka R, Gentleman R (1996) R: a language for data analysis and graphics. J Comp Graph Stat 5:299-314

Le Cren ED (1951) The length-weight relationship and seasonal cycle in gonad weight and condition in the perch (Perca fluviatilis). J Anim Ecol 20:201-209

Lester RJG (1984) A review of methods for estimating mortality due to parasites in wild fish populations. Helgol Wiss Meeresunters 37:53-64

McCallum H, Dobson A (1995) Detecting disease and parasite threats to endangered species and ecosystems. Trends Ecol Evol 10:190-193

Morales-Nin B, Ralston N (1990) Age and growth of Lutjanus

Editorial responsibility: Paul Sammarco,

Chauvin, Louisiana, USA kasmira (Forskal) in Hawaiian waters. J Fish Biol 36: 191-203

Oda D, Parrish J (1981) Ecology of commercial snappers and groupers introduced to Hawaiian reefs. Proc Fourth Int Coral Reef Symp 1:59-67

Overstreet RM, Hawkins W, Fournie J (1984) The coccidian genus Calyptospora n. g. and family Calyptosporidae n. fam. (Apicomplexa), with members infecting primarily fishes. J Protozool 31:332-339

Pacala SW, Dobson AP (1988) The relation between the number of parasites/host and host age: population dynamic causes and maximum likelihood estimation. Parasitology 96:197-210

> Post RJ, Millest AL (1991) Sample size in parasitological and vector surveys. Parasitol Today 7:141

Randall J (1987) Introductions of marine fishes to the Hawaiian Islands. Bull Mar Sci 41:490-502

Randall JE (2005) Reef and shore fishes of the South Pacific: New Caledonia to Tahiti and the Pitcairn Islands. University of Hawaii Press, Honolulu

Rigby MC, Dufour V (1996) Parasites of coral reef fish recruits, Epinephelus merra (Serranidae), in French Polynesia. J Parasitol 82:405-408

Rigby M, Font W (1997) Redescription and range extension of Spirocamallanus istiblenni Noble, 1966 (Nematoda: Camallanidae) from coral reef fishes in the Pacific. J Helminthol Soc Wash 64:227-233

Schumacher B, Parrish J (2005) Spatial relationships between an introduced snapper and native goatfishes. Biol Invasions 7:925-933

Schwindt AR, Truelove N, Schreck CB, Fournie JW, Landers DH, Kent ML (2006) Quantitative evaluation of macrophage aggregates in brook trout Salvelinus fontinalis and rainbow trout Oncorhynchus mykiss. Dis Aquat Org 68:101-113

Scott ME (1987) Temporal changes in aggregation: a laboratory study. Parasitology 94:583-595

Shaw DJ, Dobson AP (1995) Patterns of macroparasite abundance and aggregation in wildlife populations. Parasitology 111:S111-S133

Simpson EH (1949) Measurement of diversity. Nature 163:688

Torchin ME, Lafferty KD, Kuris AM (2001) Release from parasites as natural enemies: increased performance of a globally introduced marine crab. Biol Invasions 3:333-345

Torchin ME, Lafferty KD, Kuris AM (2002) Parasites and marine invasions. Parasitology 124:137-151

Torchin ME, Lafferty KD, Dobson AP, McKenzie VJ, Kuris AM (2003) Introduced species and their missing parasites. Nature 421:628-630

Vignon M, Sasal P, Rigby MC, Galzin R (2009) Multiple parasite introduction and host management plan: case study of lutjanid fish in the Hawaiian Archipelago. Dis Aquat Org 85:133-145

Wilson K, Bjorndstad ON, Dobson AP, Merler S and others (2001) Heterogeneities in macroparasite infections: patterns and processes. In: Hudson PJ, Rizzoli A, Grenfell BT, Heesterbeek H, Dobson AP (eds) The ecology of wildlife diseases. Oxford University Press, Oxford, p 6-44

Work TM, Rameyer RA, Takata G, Kent ML (2003) Protozoal and epitheliocystis-like infections in the introduced bluestripe snapper Lutjanus kasmira in Hawaii. Dis Aquat Org 57:59-66

Submitted: December 1, 2009; Accepted: March 26, 2010

Proofs received from author(s): April 30, 2010 